symmetric and Hermitian matrices. This book, while familiar to the American public, was not available to me at the time, and I did not realize that the problem proposed had been completely settled previous to the occurrence of the war.

February 9, 1920.

\title{
DICKSON'S HISTORY OF THE THEORY OF NUMBERS.
}

ON page 130 of my review of Dickson's History I speak of two pages of titles at the end of Chapter XII as "not reported on." This is an error. With the exception of certain ones marked with an asterisk which give papers not obtainable by the author the content of the papers is sufficiently indicated, the papers not being of importance to warrant more detailed report.

The phrase "list of references," on the top of page 132, is perhaps misleading. Of course the book is in no sense to be compared with the useless lists of titles of papers which the compiler may or may not have glanced at. My intention in the paragraph was to bring out the distinction which modern historians seem to make between a list of events and the relations and connections between events.

D. N. LEHMER.

\section{NOTES.}

THE December number (volume 21, number 2) of the Annals of Mathematics contains the following papers: "A property of cyclotomic integers and its relation to Fermat's last theorem," by H. S. VANDIVER; "Surfaces of rotation in a space of four dimensions," by C. L. E. Moore; "The circle nearest to $n$ given points, and the point nearest to $n$ given circles," by J. L. CoOLIDGE; "Singular solutions of differential equations of the second order," by E. M. Coon and R. L. GoRDon; "Note on a class of integral equations of the second kind," by C. E. Love; "Concerning sense on closed curves in 